\title{
LOS VIEJOS CONCEPTOS \\ Y LAS NUEVAS REALIDADES EN LA INTEGRACIÓN DE LOS DERECHOS HUMANOS
}

«... por medio de la memoria se engendra la experiencia en los hombres...». ARISTÓTELES.

(Metafísica, 980b)

1

El objeto de nuestro trabajo consiste en señalar y sugerir algunos de los caracteres significativos en la transformación de los derechos subjetivos fundamentales. Estos caracteres -muy selectivos, en el alcance limitado y sintético de estas líneas-, se observarán en la relación de su estructura formal -significado técnico jurídico-, con las fases sucesivas de su completa integración en el ordenamiento jurídico del Estado y, asimismo, en el desarrollo de sus funciones ideológicas.

La unión de las dimensiones técnica e ideológicas de estos derechos, implica algunos criterios metodológicos que es menester explicar brevemente. Se trata de señalar la naturaleza material -histórico-material-, de ambas dimensiones con independencia de su ineludible relacionalidad con la forma del poder: Esta forma posibilita la reflexividad del universal jurídico. No obstante, existe también una relación constitutiva con la materia social que se integra en el ejercicio de aquellos derechos en tanto que funciones sociales.

Materia, socialidad, que explica el contenido de los «derechos-funciones», más allá de los valores constitucionales y de sus deducciones lingüísticas. La materia y la forma se hallan unidas inextricablemente: por ello, resulta esencial reconocer, metodológicamente, el ejercitarse de sus funciones formales sin perder de vista sus elementos materiales. Resulta rutinario en la tópica académica, proceder a una analítica descriptiva de estos derechos (naturaleza, requisitos, formas de su ejercicio), como derechos deducidos de las premisas constitucionales. El contenido de estos derechos se induce del orden social con la forma de la garantía constitucional.

En la mediación de la unidad social que realiza el derecho en general, y los operadores jurídicos en particular -sean cuales fueren sus referentes doctrinales-; en esa mediación, decimos, el proceso cognoscitivo, -no el proceso de reconocimiento ideológico-, tiene 
que proceder desde aquella unidad inextricable ya señalada. El ordenamiento jurídico se encuentra subsumido materialmente en el orden jurídico de la producción social general. No puede servirnos como referencia, el pretendido orden sustancial de los denominados «valores superiores», sino el orden de la constitución material, de la constitución-producción.

2. Para la coherencia de estas notas sobre la transformación de los derechos subjetivos fundamentales, necesitamos acotar dos grandes períodos históricos. Esta delimitación, in genere, puede ayudarnos a mostrar la desigual -e incluso contrapuesta-, naturaleza de estos derechos, así como su desigual formulación técnico-jurídica:

a) El período de fundamentación moral del Derecho Natural y del constitucionalismo del Estado Liberal burgués de derecho. (Desde 1700 hasta mediados del siglo XIX). Desarrollo de los derechos subjetivos fundamentales como técnica jurídica de las leyes formales del establecimiento de la libertad y del desarrollo de la propiedad. [Recordar aquí al clásico P. Rossi: la libertad de la igualdad ante la ley es, junto a la unidad nacional, principio regulador de la unidad política de las estructuras del Estado].

b) El período de Estado Social, económico- administrativo, como organización política que gestiona técnicamente las leyes de reproducción y valorización del proceso económico global del capital. De forma creciente, el Estado, como función económica expansiva, va a ir constituyendo el componente «político» de toda una serie de parámetros económicos, jurídicos y sociales. (Desde el precio del dinero hasta la retribución mínima de la fuerza de trabajo, las condiciones generales de contratación, etc. (Es un período que abarca desde el último tercio del siglo XIX hasta nuestros días con momentos muy distintos dentro de las tendencias señaladas).

3. Esta nueva forma estatal expresa la de una organización técnico-política resultante de un doble proceso de «estatalización social» y «socialización del Estado». En esta nueva dinámica, la conceptualización de los derechos varía sustancialmente al manifestarse en la aparición de una dimensión positiva, los derechos públicos subjetivos, frente a la inicial dimensión negativa de estos derechos.

Destaquemos algunos de los elementos implicados en esta transformación:

- Transvase teórico desde el Estado Jurídico liberal kantiano hacia un nuevo Estado técnico-administrativo. 
- Subsunción del orden jurídico -como ordenamiento político-legal-, en el orden económico, de tal forma que las categorías e instituciones cobran una significación cualitativamente distinta de aquella otra que les correspondería como estrictas deducciones lógicas del ordenamiento jurídico.

- Variación en el orden económico, desde los criterios absolutizadores de la libertad de tráfico en una economía de mercado «autorregulada», hacia «tácticas» y «estrategias» de teoría económica, instrumentadas como políticas económicas de intervención en los factores y ciclos económicos.

Dejando al margen otras características no menos importantes, destacaremos la confluencia e interdependencia entre lo que se conceptualizó jurídicamente como "Sozialer Rechtstaat» y el conjunto de políticas económicas que caracterizaron el denominado "Welfare State». Habida cuenta del nuevo contexto, importa destacar la nueva «relacionalidad», circular e incluso, contradictoria, entre las categorías -jurídicas y políticas-, significadoras de lo viejo y lo nuevo, al servir a funcionalidades distintas de aquellas para las cuales fueron concebidas.

En palabras de Capograssi, la nueva función del Estado, sobre una estructura económica socializada globalmente, pone de manifiesto una fuente continua de contradicciones y contrastes entre las viejas formas y las nuevas exigencias, los viejos principios y los nuevos métodos. Es en esta perspectiva contemporánea, en esta nueva forma de la organización social donde, según indica Sforza. la ambigüedad de la relación entre la estructura y la función viene caracterizada por la ausencia de subjetividad y por la existencia de la función social de situaciones objetivas que definen el contenido esencial de los derechos subjetivos individuales.

4. Abundando en lo que estimábamos como uno de los referentes importantes, a tener en cuenta, en el proceso de transformación: la fundamentación del Estado Liberal. Esta forma pública es el resultado del contrato que estipulan seres libres. En el «uso público» de su razón por parte del hombre, se encierra la capacidad -estamos en una época de ilustración-, de obtener, en la deducción de la libertad trascendental, la igualdad, la autonomía y la universalidad de una razón práctica incondicionada.

El acto fundante del sujeto individual -de ilimitada libertad, que posee la facultad de obrar por la representación de las leyes-, se encuentra unido estructuralmente, a la posibilidad constituyente del sujeto colectivo del «género humano» y su «problema mayor...: llegar a una sociedad civil que administre el derecho en general». 
El estado jurídico resultante, «... está fundado en los siguientes principios a priori: 1) libertad de todo miembro de la sociedad como ser humano; 2) la igualdad del mismo respecto de todos los demás, como súbdito; 3) la independencia de todo miembro de una comunidad, como ciudadano» (Kant).

Sobre estas «condiciones», bajo las cuales es perfectamente posible hablar del derecho en general -una constitución civil perfectamente justa-, se determina significativamente la uniformidad objetiva de los presupuestos sociales: una univocidad lingüística que dibuja, ideológicamente, la topografía del «ser social». [Un «ser social» que en esa «significatividad» aspiraba a convertirse nada menos que en una "gemeines Wesen» -«esencia común»-. Esa bellísima teoría liberal se hacía teoría democrática].

La fundamentación liberal racional contiene, pues, su propia dualidad constitutiva: la de la separación entre la legitimación política y la unidad reguladora de producción. Ambas dimensiones, construidas sobre la referida significatividad lingüistica compuesta de diversos elementos técnicos.

En la diversa conceptualización de los derechos subjetivos hay que tener en cuenta que existe una correspondencia entre la reseñada dualidad y la evolución que se produce desde la construcción de la «teoría del Estado» sobre la dilatada fundamentación científica del iusnaturalismo racionalista hasta la formulación del moderno «constitucionalismo», tanto en su vertiente del formalismo de la teoría constitucional positivista, como, posteriormente -a raíz de la crisis de dicha teoría-, en las corrientes del antiformalismo jurídico. Estas tendencias antiformalistas dan como resultado una nueva organización de la forma y la materia a través de la tecnificación de la metodología jurídica.

Esta tecnificación ha ido cubriendo con diversas determinaciones el proceso de diferenciación -y posterior disociación-, entre el reseñado constitucionalismo formal de la razón kantiana y el constitucionalismo material que institucionaliza los derechos y ontologiza políticamente el «ser social». Dentro de la forma resultante de este proceso de transformación de los derechos subjetivos, hay que destacar, asimismo, un proceso de integración (Smend) de esos mismos derechos.

Desde los derechos de libertad, que parten del individuo -con su ilimitada libertad, en principio, frente a la esfera del Estado-, que cubren un primer momento de integración social -conforme al «principio de distribución» (Schmitt)-; hasta los sucesivos derechos «democráticos», que describen un proceso de integración política -del citoyen que vive en el Estado, esencialmente, derechos políticos; de status político (Jellinek)-, y posteriormente, los diversos 
derechos prestacionales, derechos condicionados -inscritos en las «políticas económicas» como «funciones de mercado»-. Finalmente, todos estos derechos completan su subsunción -como el propio «principio de distribución»-, en la organicidad de la estructura del Estado.

El elemento político constituyente, que no aparece en el relato -como constitucionalización de lo social-, es, sin embargo, el soporte material del proceso de integración que transforma los derechos subjetivos en funciones institucionalizadas, objetivadas socialmente, con independencia de la garantía normativa de la subjetividad individual. «La forma de formalismo del derecho no es ni puede ser ya la forma sustancial de la época clásica (...); es una forma técnica basada en una decisión, en la decisión política constituyente que se sitúa fuera del campo de visión, como «Grundnorm» (Barcellona).

5. Pasamos ahora a referirnos al segundo de los elementos que destacábamos en el proceso de transformación de los derechos subjetivos: la transformación de las categorías e instituciones jurídicas en relación con la transformación del propio Estado en el Estado económico-administrativo. Estos nuevos elementos políticos se adelantan bastante en el tiempo, materialmente, al que iba a ser, desde un punto de vista jurídico-formal, el referente privilegiado de esta transformación, la Constitución de la República de Weimar.

Se trata de la subsunción del orden jurídico, del ordenamiento político-legal, en el orden económico. Se transforma toda la estructura de condiciones que determinan recíprocamente el cálculo de la racionalidad del capital y la dimensión coactiva de las normas jurídicas desde el punto de vista de su validez empírica: «el poderío universal de la sociedad que constituye el mercado demanda, por un lado, un funcionamiento del derecho calculable según reglas racionales. Y, por otra, la extensión del mercado, que mostraremos ser una tendencia característica de aquel desarrollo; favorece, en virtud de sus consecuencias inmanentes, el monopolio y reglamentación de toda fuerza coactiva «legítima» por medio de un instituto coactivo universal, destruyendo todas las estructuras coactivas particulares que descansan las más de las veces, en monopolios económicos, estamentales o de otra clase» (Weber).

Conceptualmente, estamos en el marco neokantiano de unidad social: el derecho se convierte en un organismo técnico-procedimental, mientras que aquellos conceptos propios de la unidad democrática del Estado Liberal se transforman en la inevitable probabilidad de la reproducción de la acción social con sentido; como tal acción social, pasa a constituir la esencia sustancial del derecho, disociándose de la garantía del mismo. 
El esquema «weberiano», que nos sirve de referencia, incluye un cambio en la relación entre los órdenes sociales: es el propio orden económico -como regulador de la calculabilidad económica-, el que dota de sentido al orden jurídico. Este, el orden jurídico, no puede entenderse ya como el ordenamiento jurídico del cual, el proceder jurídico-dogmático extrae consecuencias determinantes de las conductas humanas. «Si..., el orden económico y el jurídico se encuentran mutuamente en la más íntima relación, ello significa que éste último no se entiende en sentido jurídico, sino sociológico, como validez empírica. En este caso, el sentido de la expresión «orden jurídico» cambia totalmente. Entonces no significa un cosmos lógico de normas «correctamente» inferidas, sino un complejo de motivaciones del actuar humano real» (Weber).

Estamos ante una especie de «bifrontismo» de las categorías jurídicas; es una forma de socialidad caracterizada, por un lado, por un absoluto desnivel entre el mundo de la experiencia y el individuo; y, por otro, por una convergencia inextricable entre ambos. Así se pasa desde la subjetividad trascendental normativa a la operatividad jurídico-procedimental -objetivada en el dominio sistémico-funcional-, especializada en los continuos ajustes funcionales, «reductores de complejidad».

El derecho se recompone dentro de una complejísima «pragmática social» y se expresa en la grandiosa forma vacía de los «conceptos jurídicos indeterminados». Los equilibrios sistémicos demandan adaptabilidad, flexibilidad, temporalidad, etc. Las respuestas han de ser operativas: los resultados de las operaciones hermenéuticas son tanto más relevantes cuanto mayor sea su «performatividad». «El paso del pensamiento jurídico de sistemas de conceptos a sistemas de acciones posibilita una problematización funcional de la dogmática» (Luhmann).

Las constituciones democrático-sociales -a partir de 1946- esencializan los conceptos jurídicos sobre la base de una legalidad materialmente relacionada con lo social. Legalidad que pone de manifiesto una permanente transmutación de valores como «forma» del sentido de la nueva y global constitucionalización de lo político.

La recomposición coordinada entre la realidad normativa y la «normalidad» del orden social, se realizará a través de una lógica deóntica que no investiga sobre la fundamentación de un sistema particular, sino que -desde el punto de vista de la estructura sistemática del poder político-, según A. R. Andersen, «somete a prueba su consistencia interna, verifica su adecuación lógica a su finalidad declarada y aísla y esclarece los presupuestos sobre los que descansa» (A. P. d'Entreves). [Es interesante hacer notar sobre el asunto que nos ocupa, que, en la «percepción» académica, todo el ámbito 
de la constitucionalidad material, es observado como «sociología jurídica»; diferenciado, por tanto, de la legalidad -«teoría del derecho»-, etc. En suma, las aporías de los afanes formales se multiplican; pero, en el derecho contemporáneo, la legalidad se disocia del «trascendentalismo normativo»; se explica y desarrolla socialmente, con independencia de los «valores superiores» -incluso, en flagrante contradicción con ellos-; por tanto, los empeños académicos de distinguir la «buena» legitimidad, de la «menos buena» legalidad, son esfuerzos tan vacíos como confusos...].

En consecuencia, el nuevo método de análisis de la teoría política -que introduce el funcionalismo en la sistemática de la ciencia política- determinará que el objeto del desarrollo constitucional sea absorbido por la teorización funcional del poder político -como principio de autogobierno del sistema- y por la unión del sistema cultural de valores con el sistema de roles a través de la técnica del derecho como función (Bobbio).

6. Podemos distinguir dos momentos de ordenación normativa en la historia de la ciencia jurídica:

A) En primer lugar, todo el despliegue de la organización teórica de la metafísica, dentro de la cual, el derecho natural intenta fundamentar el trabajo teórico-práctico, es decir, la política. El derecho natural constituye, en este sentido, el eje de mediación del sujeto con la historia en el espacio de lo público.

A partir del mínimo de unidad social de los individuos -según los postulados de la economía clásica- la subjetividad abstracta -como órgano de la deducción teórica del derecho natural-, introduce la conciencia moral en la historia sobre las siguientes bases:

- Los límites de la regulación económica.

- El sistema epistemológico-valorativo de la filosofía.

- La fundamentación «volitiva» de una unidad política legitimadora del proceso histórico-social.

Es el ciclo de producción y reproducción de la teoría del Estado, en el cual, según Carl Schmitt, sólo se vislumbra el Estado del constitucionalismo liberal, pero cuando por azar se unifica un proceso histórico en torno a los siguientes elementos:

- La subjetividad abstracta.

- La teoría política (determinada por la existencia de un parlamento técnico).

- El desarrollo de un orden social natural. 
B) En segundo lugar -desde el punto de vista de la organización social de la ciencia contemporánea-, nos encontramos con el problema interdisciplinar que supone la coexistencia de la ciencia política y la consideración metafilosófica del análisis lingüístico.

Hablamos de un sistema social cuya organización científica se basa en la existencia de un conjunto abierto de reglas predeterminadas -variables dependientes e independientes-; cuyo sentido consiste en la relacionalidad y la coordinación técnica de sus propias categorías internas; y cuya función estriba en la verificación empírica y constante del mantenimiento de las condiciones de normalidad y equilibrio social.

Es esta lógica, complejísima, la que sustenta los presupuestos del sistema funcional. Al referirse a la legitimación del saber «postmoderno», escribe Lyotard: «La pragmática social no tiene la simplicidad de las ciencias. Es un monstruo formado por la imbricación de clases de enunciados (...) heteromorfos. No hay ninguna razón para pensar que se puedan determinar metaprescripciones comunes a todos esos juegos de lenguajes y que un consenso revisable, como el que reina en un momento determinado en la comunidad científica, pueda comprender el conjunto de metaprescripciones que regulan el conjunto de enunciados que circulan en la colectividad». Desde el punto de vista jurídico, sin embargo, se establecen -ya dentro de la funcionalidad sociológica- «vectores de dirección o sentido» mediante los cuales la interpretación jurídica contribuye a la metamorfosis del derecho, desde su consideración primaria como instrumento de control social hasta su nueva y compleja funcionalidad como elemento de dirección social.

Esta estructura técnica de las ciencias modernas -donde la objetivación de la cultura ha pasado a dominar el concepto de naturaleza- produce un marco de circulación, cuya referencia es, exclusivamente, la de los significantes lingüísticos que facilitan la circulación. Pero como tal sistema técnico no parte de ningún principio estático que suministre postulados de valor; la circulación entre sus componentes, no se establece bajo un principio de indagación reflexiva sino tan solo entre flujos de información que organiza una compleja red telemática. Es evidente que el referido sistema no puede producir «sentido», en términos de valoración crítica, moral.

El valor de sentido se encuentra en su propia lógica relacional característica, que se especifica en su inexcusable determinación social. El «buen funcionamiento» se demuestra -en muchas ocasiones, con retórica e ideologemas ad usum populi- en la forma en que «el sentido» y «el valor» legitiman las operaciones jurídicas de reconocimiento ya reseñadas. Pero «el sentido» $\mathrm{y}$ «el valor» se explican no con las normas y los procedimientos jurídico-políticos, sino con 
el equilibrio de los factores que garantizan la reproducción global del capital.

El constitucionalismo material -y la jurisprudencia constitucional- declaran a los derechos subjetivos fundamentales, efectivamente, como elementos de un «orden objetivo de valores». Sistema de valores que fundamenta aquellos derechos sobre la base de la unidad sustancial de valores -el ordenamiento social- que une los elementos subjetivos y los objetivos en una estructura que imposibilita la contradicción entre los fines individuales y las leyes generales de socialización. El papel direccional del derecho es aquí relevante, como factor de garantía dentro de la reseñada uniformidad lingüística sin que, por ello, se oscurezca la significación de la especificidad lógica del derecho. Del derecho, como sistema de signos y símbolos coactivos, que producen un tipo específico de decisión y de discurso social.

7. Hemos de destacar sobre este particular, en la última doctrina iuspublicista española, la glosa que el profesor García de Enterría despliega para la reivindicación del «nuevo» (o «auténtico») Derecho Constitucional normativo, como sustitución del «duvergerismo fármaco-político de la ciencia política».

En efecto, el conocido jurista español -que reivindica la especificidad del derecho, disociándolo, metodológicamente, de otros saberes «sociales», estructurados como «ciencias de la realidad» en general o, como sociología, en particular- se alinea decididamente en la dinámica del Derecho Constitucional «normativo». Para ello no duda en auxiliarse de la reforma constitucional francesa de 1974, que desarrolla la justicia constitucional para destacar el carácter de norma jurídica de la Constitución y, con L. Favoreu (L'apport du Conseil constitutionnel au Droit public», 1980), para hacer resaltar la reunificación -«el Derecho constitucional se rejuridiza»-, que significa poder sobrepasar la ciencia política, para poder llegar a la formulación del «Derecho de la Constitución».

Para Favoreu, «el objeto del Derecho Constitucional se extiende y retorna así a las fuentes: ya no es sólo un Derecho «institucional»; es también un Derecho «relacional» que, como en los orígenes, incluye las libertades y derechos fundamentales, como es el caso de otros países, tales como Estados Unidos y Alemania Federal».

Al hilo de estas argumentaciones, es menester acordar la importancia metodológica de desplazar la estéril tiranía de la ciencia política, pero en la forma y medida que nos permita descubrir las articulaciones específicas del derecho y de las técnicas jurídicas dentro de la unidad de significado de la constitutiva teoría del Estado. La especificidad del proceder jurídico no puede alcanzar el límite y la extensión 
de su significado, si no es reconociendo sus mediaciones dentro del proceso de unidad de regulación social y política, La «realidad» jurídica -que no sólo comprende el ordenamiento-, es reconducible a la unidad regulativa de la ciencia; pero delimitando la forma y la materia de sus funciones.

En esta tarea de delimitación -dentro de un proceso de integración-, y teniendo en cuenta la apelación a los orígenes, es interesante recordar las observaciones de M. Hauriou, según las cuales -desde el punto de vista de los orígenes- la constitución social es previa a la constitución política, lo que viene a mostrar el modo de relación entre forma y contenido que es indicativo de la unidad entre el «ser» y el «deber ser» normativos.

Por lo mismo, pudo hablar Hauriou -con las debidas precauciones para el espíritu de la época en Francia-, del significado de la constitución política como eje de garantía de las libertades individuales -libertad y propiedad-, es decir, de la constitución social. A continuación, Hauriou señalaba la consecuencia lógica de este sentido estructural:

a) Las declaraciones de derechos son los textos constitucionales de la constitución social (del ámbito de la vida privada).

b) Los derechos individuales se convierten en instituciones constitucionales. (Précis de Droit Constitutionnel. Avertissement de la seconde édition, 1929).

Mediante estas precisiones puede establecerse que el problema, lejos de ser privativo de la recomposición unitaria del iuspublicismo, afecta a la auténtica significación de la contemporánea «teoría general del derecho». Desvelar la dimensión de este problema, pasa por resolver «une sorte de mystère qui demande explication»: misterio que consiste en comprender la correlativa conceptualización de los derechos individuales (libertades públicas), como derechos subjetivos de los individuos y como instituciones jurídicas objetivas en tanto que ideas con una realidad parcialmente independiente de las voluntades subjetivas («Précis», cit.; 2. ed., pág. 618).

Aquí aparece la ya transcrita «lógica relacional», característica del mundo contemporáneo, que establece los «módulos» de circulación: adaptabilidad; gobernalidad social; prevalencia del criterio de «lo razonable»; en suma, «validez empírica» de un derecho «relacional» que -más allá de las retóricas de su trascendentalismo normativo- renuncia a establecer «metaprescripciones comunes a todos esos juegos de lenguaje» (Lyotard). La «rejuridificación» señala como disfuncionales cualesquiera características que perturben la circulación y los ajustes técnicos, dentro del espacio de la constitución política material. 
En consecuencia, hay que destacar las mediaciones teóricas que hacen posible la relación orgánica de unidad entre la «relacionalidad» y la «institucionalidad» del concepto del derecho. Clarificar, pues, las antítesis conceptuales que se hallan en la base del concepto contemporáneo de la constitución política material: las dualidades entre legalidad y legitimidad; entre la racionalidad normativa y el «empirismo de la ideología» y, en definitiva, el «mystère» de la separación entre la esencia y la garantía de los derechos subjetivos fundamentales.

El «misterio» de los derechos vincula la existencia individual a la institucional y recompone el «deber ser» normativo de su primigenia libertad civil, burguesa, a través de la existencia de la institución: organización jurídica que tecnifica la especificación de aquellos derechos. Esta tecnificación evidencia la disociación ya transcrita entre la esencia del derecho -el contenido inducido de la unidad de la materia social como objetivación externa-, y la garantía del derecho, en cuanto técnica de legitimación indeterminada; esta indeterminación se concreta en función de un contenido que se produce al margen de la subjetividad individual. [Si seguimos la metodología de A. Muralt, esta distinción entre la garantía y la esencia de los derechos fundamentales -art. 53.1, CE- recrea la propia separación que se desprende del pensamiento medievalista cartesiano entre la «libertad de ejercicio» y la «libertad» de especificación (En la cuarta Meditación Metafísica, «De lo verdadero y de lo falso»)].

Todos los elementos de estas transformaciones tienen también su referencia obligada en la crisis que, desde Weimar, afecta a la propia estructura o bloque de legalidad. Como ya se ha indicado, esta crisis determinaba las formas de conversión de las técnicas del Estado Liberal en aquellas otras propias del Estado burocrático, técnico-administrativo. Las nuevas funciones son percibidas en el iuspublicismo como la totalización normativa -jurídico constitucional-, de todo el espacio político, superando la vieja indagación de la fílosofía política. Sin embargo, lo que se percibe técnicamente como juridificación se desconecta del proceso global de racionalización que determina el sentido de la constitución material y las reseñadas nuevas funciones que lo acompañan: constitucionalización de la gobernabilidad social de la economía y la constitucionalización administrativa de la política.

Esta interconexión forzosa -como estructura material que identifica Estado y sociedad- reproduce jurídicamente la constitución social como ya resaltara Hauriou. Los derechos subjetivos fundamentales se integran -como cualquier otra categoría técnico-jurídica-, en la conceptualización normativa de un orden de valores. 
En esta estructura normativa, la fuente del derecho deriva del conjunto de fuerzas sociales que construyen, por sí mismas, las expresas manifestaciones jurídicas y la jerarquía de su existencia. Se trata, como señala Negri, de un proceso evidentemente formal, pero caracterizado sobre la base de su momento fundacional; en consecuencia, se expresa de forma constante su contenido histórico-positivo. Se trata del significado de la constitución material sobre el que escribe Negri: «la integración (la segunda), revela su cara positiva: lleva a la luz la totalidad de las relaciones sociales, las positiviza de manera concreta $\mathrm{y}$, al margen de toda nostalgia por la espontaneidad, consigue unificar y configurar unitariamente el acto materialmente productivo del derecho». Aquí se evidencia el carácter evanescente de cualquier ley que, sin integrarse en el sistema jurídico, aspire a ejercitar, exclusivamente, la función de garantía de la libertad y la propiedad; también la integración del principio de distribución en la estructura político-estatal, convirtiéndose en una referencia exclusivamente ideológica.

8. La diferencia de los sistemas jurídico-políticos que hemos considerado, pone de relieve -según la feliz expresión de Forsthoff-, «la mala pasada que se ha jugado a los derechos fundamentales». En efecto, éstos pasan a ser considerados ahora como derechos fundamentales positivos: principios positivos o positivación de valores como consecuencia de haber sido subsumidos en la técnica normativa de su consideración valorativa. Se produce, pues, la quiebra de la legalidad inmanente propia de la primera forma teórica de los derechos fundamentales.

Como indica Forsthoff, se produce una metamorfosis desde los derechos de libertad hasta el concepto de normas obligatorias en conexión con la relación social. Esto comporta, a su vez, un cambio en el proceso de interpretación: ahora se convierte en el mecanismo técnico-interpretativo de la relación social general.

Desde el punto de vista político, esta transformación supone la unión del principio liberal con el principio democrático (art. 1.1 CE); desde el punto de vista jurídico, supondrá la «crisis de legalidad».

Esta crisis se expresará en el doble sentido que adoptará el concepto de los derechos subjetivos fundamentales. Por un lado, dentro de la estructura de la socialidad general, esta categoría jurídica ejercerá la función regulativa del ámbito de la libertad individual -con el matiz que incorpora la cláusula de la «reserva legal»-, al margen de la intervención del Estado; por otro lado, dicha función se desarrollará bajo la protección absoluta de la soberanía del Estado. Según Carl Schmitt, esta dualidad tendrá como consecuencia la desnaturalización político-legal tanto del principio liberal como el principio democrático. 
Todas las transformaciones históricas que nos sirven de referencia -la crisis del Estado parlamentario-liberal y el sustancial cambio de las relaciones de producción entre 1880 y 1929; crisis económica, industrialización e imperialismo- operan, efectivamente, una crisis de la legalidad; crisis que expresa «un cambio en la función de la ley» (F. Neumann). Cambio legal que toma cuerpo en el trasvase que se efectúa desde la ley general hasta las medidas concretas del soberano; desde el concepto de ley formal racional hasta el concepto de ley politica.

Toda esta situación técnica está caracterizada, precisamente, por la distinción entre la ley formal racional -que constituye la base de toda la «idealidad normativa»; "ratio» versus «voluntad»-, y la ley política de contenido material, que remite a la separación entre legalidad y legitimidad o, lo que es lo mismo a la época de las medidas concretas, de las «leyes medidas» -«Massnahme-Besetze: verdadera «ration essendi» del Estado administrativo-; o los «decretos-leyes» como expresión de la legitimación alargada del poder estatal.

Esta distinción capital -expresión de tantas separaciones- es puesta de manifiesto por Forsthoff, cuando afirma que «las transformaciones sociales no afectan a la libertad en cuanto tal, sino que limitan las condiciones de su ejercicio». Si tenemos en cuenta, por un lado, la disociación entre legalidad y legitimidad y, por otro, las construcciones teóricas de Hauriou y Schmitt sobre la «institucionalización de los derechos fundamentales», nos encontramos con una conceptualización de los derechos fundamentales -«el privilegio», según Forsthoff-, como un resultado de la conexión casual entre hechos sociales; en otras palabras, una objetivación social realizada, "a posteriori» de cualquier precondicionalidad normativa -por ejemplo, la igualdad jurídica cualificada sobre la base de hechos sociales objetivos y regulada por la naturaleza normativa del decreto-ley-. Desde el punto de vista de la teoría política, todo lo anterior halla su correspondencia en la posibilidad de distinguir entre la constitución y la realidad constitucional.

Los derechos fundamentales, como categoría jurídica, se transforman en funciones de parámetros sociales -no constitucionales-, aunque se formalizan como garantías. Según la teoría institucional -en la cual la subjetividad aparece como personificación de la idea objetiva-, «los derechos y deberes no se vinculan ya con la voluntad de personas legalmente iguales, sino más bien con hechos objetivos. Lo decisivo ahora es la posición que ocupa el hombre en la sociedad» (E Neumann). En el mundo contemporáneo -época de la constitucionalización material del trabajo y de la autovalorización social del capital como elemento de igualación formal dentro de la sociedad-, la ciencia jurídica, y la misma categoría de los derechos subjetivos 
fundamentales, se subsumen en un proceso dependiente de los ritmos constitutivos del poder, identificando sus desarrollos -desde la unidad de la ciencia social- y coadyuvando en la doble tarea de la interpretación y la fijación reproductora de los límites globales del sistema.

9. Los derechos subjetivos fundamentales han perdido su idílico estatuto de derechos de autodeterminación privada e individual, para configurarse como derechos de participación en el proceso de planificación de las necesidades sociales. Como ya se ha indicado, la posición de los sujetos en la estructura social, altera sustancialmente el alcance y contenido de esa participación, disociada de la garantía del ejercicio de esos mismos derechos.

Para la ciencia del derecho -como «scientria iuris», ampliamente reflexiva (Orestano)-, lo importante es ahora la reestructuración positiva del positivismo; la instrumentación positiva del dogma de la ley en el ámbito del Estado social de derecho. En definitiva, hablamos de mecanismos de integración: un sistema de producción jurídica que recompone, de forma permanente, el conflictivo equilibrio entre mandato y consenso, entre «reglas» $\mathrm{y}$ «hábitos» (Hart); se trata de una forma de ordenamiento jurídico que se desarrolla de manera difusa, pero expansiva, hasta recubrir la totalidad de la forma social.

En efecto, si queremos comprender, con rigor, «la mala pasada que se ha jugado a los derechos fundamentales» -en la citada expresión del juez Forsthoff- no se puede olvidar la presión a que fue sometida dicha categoría por las sucesivas fases de integración -a las que ya nos hemos referido brevemente- que transcurren desde la integración -no constituyente- de aquellos derechos en la estructura histórica del «antiguo régimen», hasta una nueva forma de «lo político» en la que la legalidad se halla directamente referida a lo social.

Significación jurídica integradora, que se observa en la transformación que se desarrolla desde los «derechos-deberes» hasta los valores (superiores). La concreción de estos «valores» se realiza a través del principio organizativo -división de poderes-; el principio hermenéutico, como forma de interpretación y de la subsiguiente homogeneización del ordenamiento, y el principio de la soberanía (según el criterio de la Reforma Constitucional).

Se constata, asimismo, esa función jurídica integradora para la vigente Constitución española; en la funcionalidad de los «derechos-deberes» (valores), con respecto a determinados axiomas preconstitutivos -es decir, pertenecientes a la historia político-jurídica del régimen franquista-; por ejemplo axiomas del «orden político y la paz social» (art. 10.1. CE., en relación a la Ley de Orden Público de 30 de julio de 1959, en cuyo art. V se destaca la técnica del ejercicio 
de los derechos fundamentales y su funcionalización a las adjetivaciones políticas y económicas del «orden público y la paz social».

Significación integradora, en definitiva, que es una exigencia de la unificación fundamentadora del proceso económico y sus correspondientes ajustes funcionales al «contenido esencial» de los derechos fundamentales. Dicho «contenido esencial» pasa a convertirse -en virtud del art. 53.1, CE.,- en un parámetro de base para toda la producción normativa que afecte a derechos fundamentales. En consecuencia, los derechos subjetivos fundamentales se hallarán limitados por el propio contenido esencial de los mismos; contenido esencial, en efecto, que nunca vendrá determinado por la existencia de la garantía de la subjetividad individual. [Verbigracia: desde el derecho de huelga hasta el derecho de propiedad sobre el suelo edificable según la Ley 8/1990, de 25 de julio, sobre «Reforma de Régimen Urbanístico y Valoraciones del Suelo», modificada, posteriormente, por R. D. Legislativo 1/1992, de 26 de junio (B.O.E. 30-6-92), en donde se advierte claramente la «configuración básica de un derecho fundamental» regulado según la técnica instrumental de una forma de legalidad que caso por caso intenta afrontar con igualdad los viejos problemas que ahora se suscitan en la racionalidad jurídica entre el derecho subjetivo de la propiedad privada, el interés general del suelo por parte de los poderes públicos y las plusvalías urbanísticas afectantes a la comunidad (Introducción). En base a la técnica de la Reserva Legal del art. 53.1, C.E., se trata, por remisión delegativa, de la constitución de un modelo subjetivo cuya esencialidad se desvincula de la propiedad subjetiva y se afecta esencialmente a los fines del ordenamiento estatutario urbanístico como facultades fundamentales del ius aedificandi en cuanto derechos y deberes distribuidos por la legalidad del Planteamiento. En definitiva, hundimiento de la técnica jurídico-liberal, C.C., art. 348 a 350, y predominio absoluto de la técnica jurídico-administrativa cuya subjetividad esencial reside en los derechos-deberes urbanísticos: derecho a urbanizar, derecho al aprovechamiento urbanístico, derecho a edificar y, por fin, el derecho a la edificación (vid., al respecto, Rico Fernández, J. C., Rvta, Catastro, Centro de gestión catastral y cooperación tributaria, Madrid, año 11, no. 7, 1991, págs. 38, 39)].

La estructura técnica, teórica, de estos procesos de integración producen una específica «ideología integradora»-desde el derecho hasta los «operadores jurídicos»-, como elementos de una lingüística, general y operativa, que trabaja sobre las nuevas realidades con los viejos supuestos del mundo jurídico liberal. En la funcionalidad lógica e ideológica de los derechos fundamentales, resulta esencial poner de manifiesto la absoluta configuración jurídica de las instancias de mediación; en efecto, tratándose de la constitucionalización 
global del trabajo, los análisis se sustentan sobre la constante hipostasis entre los requerimientos de la relación social general y las categorías de la antigua metafísica política del liberalismo burgués. (Ordenada sobre la preexistencia, lógica y temporal, de los derechos subjetivos; el derecho de propiedad era la categoría central de la «sociedad civil»).

10. La pérdida de contenido sustancial de los derechos subjetivos fundamentales se encubre tras el incremento de su virtualidad ideológica. Las antiguas ideologías ilustradas constituyen, teóricamente, la sustancia de los derechos; desde la razón, se deduce la igualdad jurídica, técnicamente, las dimensiones empíricas del orden social, en la dirección de su conservación y reproducción.

Si hablamos de transformación del Estado de Derecho -según U. K. Preuss, siguiendo el pensamiento de Hesse-, lo hacemos evidentemente porque su definición como "sistema de recursos técnico-jurídicos que garantizan la libertad en los términos de la ley» (Forsthoff) -como sistema limitador y delimitador de los poderes públicos-, no se ajusta ya a la realidad histórico: en el derecho, sin embargo, sus categorías sobreviven como referencias privilegiadas de toda la simbólica de las garantías.

En la nueva estructura legal, los derechos fundamentales pasan a ser la sublimación de la sustancialidad de los intereses individuales por garantizar. (Negri). El concepto de ley asume, de manera conjunta, la organización de la validez y la eficacia. La validez de la ley ya no está exclusivamente referida al ordenamiento, como algo «específicamente normativo» (Kelsen). Toda la producción normativa está mediada socialmente; subsume en su circulación técnica, «la fuerza normativa de los hechos»(Jellinek).

La propia noción de legalidad no es funcional a la tutela de los intereses singulares contemplados en los derechos; por el contrario, formaliza esos mismos derechos a través de la intervención, activa y positiva, en la realidad social para construir directamente su orden: «normalizando» los antagonismos y diluyendo lo «excepcional» en la continua circularidad del ser social. De la ley al derecho:«el derecho se convierte en un subsistema del sistema social, al que se atribuye la función de despolitizar el conflicto -los conflictos de «dominio» se reducen a conflictos de «mando» (Agnoli)-, y canalizarlo por el conducto de los procedimientos jurisdiccionales (Barcellona).

El Estado social hace de toda la sociedad el «medium»de la apropiación, cambiando el objeto de la explotación en «sujeto» de la gestión de la acumulación social. El resultado, según Negri, será el reformismo político de una estructura jurídica ordenada sobre los principios de libertad, igualdad y sociabilidad; como elementos ideológicos 
de la forma que desliga una socialidad caracterizada en los viejos términos iusnaturalista de la retórica constitucional.

Carl Schmitt escribía, en 1972, que los derechos subjetivos fundamentales -en su formulación política y técnico-jurídica contemporánea- eran deudores y herederos de la crisis ideológica del Estado burgués de derecho y la quiebra de las correspondientes categorías jurídicas y políticas. La crisis produjo una indeterminación lingüística, de tal alcance, que originó, no sólo el desconocimiento de la relación entre la teoría del Estado y el derecho constitucional, sino también, la permanencia ideológica de los viejos conceptos para las nuevas realidades.

La crisis de alcance del racionalismo occidental, se ha transformado en la crisis de la modernidad; por tanto en una crisis «permanente», larvada, que expresa el "fraccionamiento del universal... y el declive actual de los relatos de legitimación sean éstos tradicionales o «modernos» (Lyotard). En este clima cultural de «incredulidad con respecto a los metarrelatos»-de permanente «transmutación de valores», como valores de cambio- se produce la unión del lenguaje de las viejas categorías con la moderna técnica administrativa.

Aquellas venerables categorías, liberales e ilustradas, se hallaban subsumidas formalmente en el proceso económico; ahora, sin embargo, la estructura jurídica se encuentra subsumida materialmente en la producción; en la actualidad, cuando la producción se ha hecho social, todo es productivo (Negri). También, desde luego -como función importantísima-, el derecho como organización técnica, avalorativa, que garantiza el futuro en la reproducción permanente del presente. En consecuencia, el moderno concepto del derecho puede situarse en la dinámica dialéctica de la legítima valorización de todo lo nuevo, sin partir de ningún principio de valor.

Este proceso expresa la separación entre las realidades conceptuales de la legalidad y la legitimidad y verifica el sustancial cambio de naturaleza de los derechos subjetivos fundamentales: de artificios técnicos, para la garantía de las esferas de la libertad y la propiedad pasan -en su consideración como derechos públicos subjetivos- a ser derechos funcionales tutelados por el ordenamiento jurídico del Estado.

La directa relación entre la legalidad y la socialidad expresa esa intensa transformación de los derechos en la separación entre la esencia y la garantía de los mismos: el «contenido» se objetiviza socialmente paralelamente a la garantía, que permanece en el sistema de recursos jurisdiccionales. La garantía cobra una nueva dimensión funcional: la que le proporciona un contenido que no es subjetivo, sino que, por el contrario, se halla objetivado técnicamente. Este proceso se expresa con arreglo a un orden de valores que la subjetividad individual interioriza como deberes jurídicos. 


\section{BIBLIOGRAFÍA}

Agnoli, J., «La transformación de la democracia», México, 1791.

Barcellona, P., «I soggetti e le norme», Milano, 1984.

- «Postmodernidad y Comunidad. El regreso de la vinculación social», Torino, 1992.

Bobbio, N., «Dalla struttura alla funzione. Nuovi studi di teoria del diritto», Milano, 1977.

Bonnard, R., «Les droits publics subjectifs des administrés», Revue du Droit Public, París, 1932.

Capograssi, G., «La ambigüedad del Derecho contemporáneo», en VV.AA., «La crisis del Derecho», Buenos Aires, 1961.

Cesarini Sforza, W., «Idee e problemi di filosofia giuridica. V. Avventure del Diritto soggettivo», Milano, 1965.

Dabin, J., «Droits subjectifs et subjectivisme juridique», Archives de Philosophie du Droit, T. IX, París, 1964.

De Muralt, A., «Kant, le dernier occamien. Une nouvelle définition de la philosophie moderne», en Revue de Metaphisique et de Morale, $\mathrm{n}^{\circ} .1,1975$.

- «Souveraineté et Pouvoir», en «La structure de la philosophie politique moderne: d'Occam a Rousseau», Cahiers de la Revue de Théologie et de Philosophie, Ginebra, 1978.

Eisenmann, Ch., «Une nouvelle conception du droit subjectif. La théorie de M. Jean Dabin», Revue du droit public et de la science politique, París, 1954.

Favoreu, L., «L'appot du Conseil constitutionnel au Droit publuic», Rev. «Pouvoirs», no . 13, junio, 1980.

Forsthoff, E., «Sociedad industrial y Administración pública», Madrid, 1967.

- «El Estado de la sociedad industrial», Madrid, 1975.

Gallego Anabitarte, A., «Derechos fundamentales y garantías institucionales: Análisis Doctrinal y Jurisprudencial (Derecho a la educación; Autonomía local; Opinión pública), Ed. Civetas, S.A. - Universidad Autónoma de Madrid, Madrid, 1994.

García de Enterría, E., «La Constitución como norma y el Tribunal Constitucional», Madrid, 1981.

Giannini, M. S., «El Poder público. Estados y Administraciones públicas», ed., Civetas, Madrid, 1991.

Guastini, R., «Le fonti del diritto e l'interpretazioni», Giuffrè, Milano, 1993.

Hart, H. L. A., «El Estado de Derecho», Buenos Aires, 1963.

Hauriou, M., «Les principes de Droit public», París, 1910.

- «Précis de Droit constitutionnel», París, 1929 (2 ${ }^{\mathrm{a}}$. ed.).

Jellinek, G., «Sistema dei diritti pubblici subbiettivi», Milano, 1912.

- «Teoría General del Estado», Buenos Aires, 1973.

Kant, I., «Lo bello y lo sublime», «La paz perpetua», Madrid, 1946.

- «Fundamentación de la Metafísica de las Costumbres», Madrid, 1946.

- «Filosofia de la historia», México, 1981. 
- «La Metafísica de las Costumbres», Madrid, 1989.

Kelsen, H., «Teoría general del derecho y del Estado», México, 1949.

Lyotard, J. F., «La condición postmoderna», Madrid, 1989.

Luhmann, N., «Sistema jurídico y dogmática jurídica», Madrid, 1983.

- «La differenziazione del diritto», s.e. Il Mulino, Bologna, 1990.

Mortati, C., «La Costituzione in censo materiale», Milano, 1940 ( $1^{\text {a }}$. ed.).

Negri, A., «L'empirismo dell'ideologia. Sull'ultimo libro di Norberto Bobbio», Rvta. Critica del Diritto (Stato e conflitto di clase), Milano, 1977.

- «Marx oltre Marx», Milano, 1979.

- «Fin de siglo», Barcelona, 1992.

Neumann, F., «El Estado democrático y el estado autoritario» (Ensayo de Teoría Política y Legal), ed. Paidós, Buenos Aires, 1957.

Orestano, R., «Edificazione del Giuridico», s. è Il Mulino, saggi 354, Milano, 1989.

Passerin d'Entreves, A., «Derecho Natural», Aguilar, Madrid, 1972 (1 ${ }^{\text {a }}$. ed.).

Preuss, U. K., «El concepto de los derechos y el Estado de bienestar», en VV.AA., «Problemas de legitimación en el Estado Social», Madrid, 1991.

- «Die Internalisierung des Subjekts. Zur Kritik der Funktionsweise des Subjektiven Rechts», Suhrkamp, Frankfurt a. M., 1979.

Rawls, J., «Justice et Démocratie», Edtns. du Seuil, París, 1993.

Rossi, P., «Cours de Droit Constitutionnel», Oeuvres completes, 4 vols., ed. M. P. Parée, París, 1966.

Rubio Llorente, F., «La forma del Poder. Estudios sobre la Constitución» (Rango de Ley, fuerza de Ley, valor de Ley. Sobre el problema del concepto de Ley en la Constitución), C.E.C., Madrid, 1993.

Schmitt, C., «Teoría de la Constitución», Madrid, 1934.

- «Legalidad y legitimidad», Madrid, 1971.

- «Freiheitsrechte und institutionelle Garantien der Reichverfassung», en «Das Problem des Hürters der Verfassung und der verfassungsrechtlichen Garantien», Berlín, 1973.

Smend, R., «Constitución y Derecho Constitucional», C.E.C., Madrid, 1985.

Weber, M., «Orden jurídico y Orden económico», en «Economía y Sociedad», págs. 251-273, México, 1944. 
$\Delta$

DOXA 15-16 (1994) 